\title{
The Medical Social Worker: A Neglected Ally in the Management of Patients with Burn Injuries
}

\author{
Kolawole Olubunmi Ogundipe, ${ }^{1}$ Innih Kadiri, ${ }^{1}$ Amarachukwu Chiduziem Etonyeaku, ${ }^{2}$ Tolulope Aduloju ${ }^{3}$ \\ 1. Plastic and Reconstructive Surgical Unit, Department of Surgery, Ekiti State University / Ekiti State \\ University Teaching Hospital, Nigeria \\ 2. General Surgery Unit, Department of Surgery, Obafemi Awolowo University \& Ekiti State University \\ Teaching Hospital, Nigeria \\ 3. Department of Social Work, Ekiti State University Teaching Hospital, Nigeria
}

Correspondence to: Dr. Kolawole Olubunmi Ogundipe; email: koogundipe@hotmail.com

\begin{abstract}
Summary
Burn injuries come with enormous challenges and devastation to the victims. The consequences get worse when multiple members of a family are involved. Social supports are necessary, especially where health financing is mainly through out-of-pocket expenditure. The use of Medical Social Workers (MSW) in burn care in our region is limited, and their roles are poorly or inadequately reported. This study appraises the role of MSW in the multidisciplinary management of burn patients. We report the management of an impoverished family of five who sustained varying degrees of burn injuries, and the role MSW played in their care. Beyond being a routine discharge planner, the MSW provided social support, psychotherapy and rallied community support, which translated to an improved outcome for the patients. Involving MSW in burn care provides great benefit to patients. Burn surgeons are therefore
\end{abstract}

\section{Introduction}

Burn injury is one of the most devastating injuries anyone can sustain and remain alive (1), though with widespread and debilitating consequences. Its sequelae include morphological changes, psychological and functional impairments, as well as social stressors like posttraumatic stress disorder, pain, shock, sepsis, and altered physiological function in the immune and emergency response systems $(2,3)$. Even at the time of discharge, the burn model system of Fauerbach et al. (3) reveals that there could be clinically significant psychological distress in a third of patients who sustained major burns. It becomes more worrisome when more than one person in a family is affected. The psychosocial, financial, mental, and physical consequences can far outweigh the resolve of the burn-injured patients to cope.

In particular, costs associated with management of burn injury are often high. Chris and Peter (4) put the cost for managing an average adult burns patient at US\$73,532. encouraged to use the added value of MSW on their teams.

Keywords: Burn, Injury, Medical social worker, Healthcare financing

Ann Afr Surg. 2020;17(3):126-129

DOI: http://dx.doi.org/10.4314/aas.v17i3.8

Conflicts of Interest: None

Funding: None

(C) 2020 Author. This work is licensed under the Creative Commons Attribution 4.0 International License

Submitted: 14 October 2019

Revised: 11 March 2020

Accepted: 30 March 2020

Online first: 29 May 2020

Procuring burn care is a big challenge in Nigeria where the living wage per individual is US\$119 per month (5), the gross domestic product is US\$2,028 (6), and a significant population earns US\$50 per month ('minimum wage'). Further, the unemployment rate was estimated at $23.13 \%$ in the third-quarter 2018 by the National Bureau of Statistics (7). These are issues of concern in Nigeria where out-of-pocket expenditure (OPE) has been the principal mode of financing medical care, up to $65 \%$ in some studies (8).

For the best outcome, management of burn injuries requires a multidisciplinary approach (9). The burn team will not be deemed complete without the medical social worker (MSW). Atanesian of the North Carolina Jaycee Burn Center highlighted the roles of the MSW to include social support and counselling to patients and their families, suggesting appropriate services, addressing problems or concerns as they arise throughout hospitalization, facilitating patient's release from the 
hospital, assisting with reintegration into the community, and providing tools and resources for the patient to reclaim life once again (10).

In the management of burn injuries in our facility, social workers were only called upon to facilitate patients' release from the hospital and recover unpaid bills. They were hardly involved in the management of the burninjured patient. However, following the presentation in our institution of a family of five with varying degrees of burn injuries, the devotion of MSW came handy in facilitating the total care.

\section{Methods}

This study is a descriptive report of the role played by medical social workers over two months in the management of five patients who sustained varying degrees of burn injuries and who were admitted into our facility, Ekiti State University Teaching Hospital (EKSUTH), in south-west region of Nigeria. We obtained informed consent from the father on behalf of the patients before we included them in this study. The Hospital Ethics and Research Committee's approval was also sought and obtained before the study commenced (ERC No. 2019/09/0018). We retrieved records of the patients' biodata (name, age, sex, place of work, and abode, religion), history of presenting complaint, clinical profile, and treatment up to discharge, and entered them into a spreadsheet. The hospital has two certified MSW, assisted by four clerical assistants, with access to a shuttle bus and a standby driver. The involvement and record of the activities of the MSW and their impact on care were also recorded. We employed the core competency areas of the medical social workers' services as described by Atanesian (10) in evaluating the extent of involvement as well as the completeness of services MSWs availed to the patients.

\section{Case Study}

A family of five sustained varying degrees of burn injury following a cooking gas explosion at their home, a twobedroom apartment in a block of flats. They suffered the injuries while the mother was attempting to light a gas cooker in their kitchen, unaware there was a gas leak from the system. The resultant explosion primarily affected her and her three children who were with her in the kitchen. Her husband sustained burn injuries while trying to rescue her and the children.

The mother, a 38-year-old female petty caterer, sustained $20 \%$ mixed thickness burns to the face and both upper and lower limbs. First child, a 10-year-old girl, had $27 \%$ mixed thickness burns involving the head and neck, both upper and lower limbs, with an inhalation injury. The second child, an 8-year-old boy, sustained burns to the head and neck, both upper and lower limbs, with estimated total burn surface area (TBSA) of 17\%. The 4year-old youngest child had $27 \%$ burns involving the head and neck, both upper and lower limbs and part of the trunk, with an inhalation injury. The father, a 48-yearold launderer, had partial-thickness burns involving the face and the right upper limb with TBSA of $9 \%$.

The family lived and worked at Mowe in Ogun State about $100 \mathrm{~km}$ from Lagos, the economic capital of Nigeria. Our facility, also located in south-west Nigeria, is about $268.4 \mathrm{~km}$ from Mowe. They were initially managed at two private hospitals before they were referred to our facility, on the father's request, on the 4th day post-injury because they could not finance the needed care at the referral hospital. We managed the father as an outpatient while the other four were admitted. They were discharged home on the 17th day of admission, and followed up in the clinic. However, they were lost to follow-up after a few clinic sessions.

\section{Role played by social workers}

On presentation, the family had no funds with which to pay for treatment; initial access to care was supported by the hospital's policy of providing care without any hindrance in the first 24 hours of admission. By the following day, the plastic, burn and reconstructive surgery unit invited the medical social works department to co-manage the patients, given the socio-economic and psychological straits they were passing through: they had lost their home and had no funds to access care. The MSWs evaluation revealed that the husband had no living relative and that the wife, too, had been long ostracized by her own family. The index family lived far away and detached from their community and thus had a poor connection with their home community.

The MSW moved in immediately to provide the patients with social support. They sought donations of items of clothing for the patients, as they had presented to our facility without any extra clothing. MSW helped the patients obtain food, besides provisions from the hospital kitchen, and to procure toiletries and similar items.

On the 3rd day of admission, the MSW facilitated transport for the father to visit his home community and seek financial support. When contacted, the traditional ruler of the community referred the MSW to the community's progressive union, a body that provides an avenue for mutual aid, contributory welfare, security and leadership within the town. The union asked for donations in cash and kind from members of the community. The MSW were the liaison between the 
patients' host community and the hospital, ensuring a constant flow of funds for their management. Later on, the MSW secured a sum of money from the Ekiti State Government through its periodic health financing intervention program to needy patients.

On day 3 of admission, the youngest child died from severe pneumonia, and the MSW provided psychotherapy and counselling for the parents. Subsequently, the MSW participated in the clinical meetings and briefings held on behalf of the patients and occasionally joined the ward rounds. On discharge, the MSW took up the barge of the discharge planner and facilitated their joining social support groups.

\section{Discussion}

Burn injuries are devastating and debilitating injuries requiring multidisciplinary care in a burn center; no single specialist can manage the multisystem injuries that arise following burn injury. Burn injury management is not limited to medical or surgical care but also involves a psychological assessment of the patient and the family (11). Survivors of burn injuries deal with psychosocial issues like adapting to physical limitations and permanent changes, coping with grief and loss, traumatic stress, anxiety, pain, sleep disturbance, depression, body image concerns, among others (12). Given these psychosocial issues, the role of MSW cannot be underestimated in the care of burn patients. Thornton and Battistel (13) illustrated the significance and the responsibilities expected of social workers in a study; they suggested that the social worker could assist in the psychosocial adjustment of burn patients during hospital admission, both in the acute and rehabilitating phases. Suggested approaches include a case-management style and establishing support groups. Blakeney et al. (14) observed that increased likelihood of physical survival had led to more concern for the potential psychological morbidity of the burn survivor, and therefore devised a philosophy of psychosocial rehabilitation for patients with severe burns. Waqas et al. (15) noted that social support played a significant role in maintaining the physical and mental health of patients with burn injuries. Patients tend to heal faster with shorter treatment duration when families are present and provide the necessary assistance, as burn treatment and recovery can still be long and arduous, even with family support. In a study on psychosocial adjustments of patients after burn injury, interdisciplinary cooperation between plastic surgeons and psychosomatic specialists could optimize early intervention with patients exposed to social maladaptation (16). Waqas et al. further noted that burn patients reported lower scores on social support from their significant other, family, and friends than their healthy counterparts (15).

Our patients did not even have any family, friends, or others to lean on to for support. The social workers support lessened the would-have-been negative health outcomes for them. MSW offered psychotherapy and counselling to the father and mother after the loss of their youngest child. It is not unusual to erroneously consider children as minors who may not yet appreciate the implication of the loss of a sibling. As such, the other siblings did not receive the psychotherapy.

Managing these patients was not the first time the MSW were involved in management of patients. However, the knowledge of their established roles is deficient in management of burn patients. As Linton et al. remarked (17), social workers mostly wear the discharge planner hat. It is therefore not unusual for us to call on them to help plan a patient's discharge, recover unpaid bills and assist with reintegrating the patient in the society. We rarely involve them in the care of burn patients from the outset of management (in the acute phase of care). Barrett (18) recommends referring burn patients to social work as soon as possible after admission (at least within the first 24 hours). Early referral of these patients ensured they were provided appropriate psychosocial crisis care and support, and their immediate practical needs were addressed as early as possible. The MSW obtained financial support for the patients, mainly by engaging the patient's home community, ultimately lowering the cost of care. Fraser et al. in their review of studies reported ten studies where social workers engaged community resources on behalf of patients and their families, and noted that seven of those studies demonstrated findings favoring integrated care (19).

Without financial support, access to healthcare would have been impossible for the patients, thereby increasing their potential morbidity and mortality and escalating the attendant cost of care. Steketee et al. (20) in their study noted that interventions involving social workers, whether through sole delivery, team leadership, or core membership on interprofessional teams, had positive effects on health outcomes and were less costly than usual care that did not include substantial social work services. Invariably, the MSW were still required to wear the discharge planner hat, but they equally helped the patients join a social support group. Establishing social support groups provides avenues for burn survivors and their families to discuss subjective experiences, as well as receive information on various coping techniques (21). 
We used the Atanesian core competence area for social work assistance to families (10) to assess the completeness of the role of MSW in this study. The MSW were thorough in discharging their duties to the patients. These duties also cut across the five essential domains of social work, as illustrated by Browne et al. (22): increasing screening and prevention, addressing economic and environmental stressors in healthcare, improving care management and coordination, promoting interventions tailored for vulnerable populations, and facilitating successful care transitions. These are models of health social work that can leverage healthcare systems to address social and community factors shaping health outcomes (22). Marino et al. (23) worked on developing a conceptual framework that would guide implementation of a large-scale calibration study that will provide a computerized adaptive test for monitoring the social impacts of burn injuries during recovery. The intervention of MSW can then be better tailored against such established social impacts when such monitoring tools are available, rather than carrying them out empirically.

\section{Conclusion}

The MSW's responsibilities go beyond psychosocial support, planning for discharge, and debt recovery. The MSW is a mobilizer who helps to rally community support for burn patients, even to clients from disjointed families. This study shows the beneficiary participation of MSW in the multidisciplinary care of patients with burn injuries. With more evidence suggesting improved outcome for patients, families and communities in integrated patient care and the added value of social workers on such healthcare teams $(19,22,24)$, burn surgeons in similar settings are advised to get more participatory involvement of the MSW in their practice.

\section{Acknowledgement}

The authors warmly acknowledge and appreciate the roles played by Mrs CO Omole of the Department of Medical Social Services of the Ekiti State University Teaching Hospital, Ado-Ekiti.

\section{References}

1. Ogundipe KO, Adigun IA, Solagberu BA. Economic burden of drug use in patients with acute burns: Experience in a developing country. J Trop Med. 2009. Article ID 734712.

2. Adigun IA, Ogundipe KO, Abiola OO. Amputation from burn following epileptic seizure. J Surg. 2008;3(4):78-81.

3. Fauerbach JA, Lezotte D, Cromes GF, et al. Burden of burn: A norm-based inquiry into the influence of burn size and distress on recovery of physical and psychosocial function. J Burn Care Rehabil. 2005;26:21-32
4. Chris SA, Peter KMM. The true cost of burns. Burns. 2012; 38(7):967-974.

5. Nigeria Living Wage Individual. Trading Economics. https://tradingeconomics.com/nigeria/living-wage-individual Accessed 22 August 2019.

6. World Bank Group. GDP per capita (current US\$) 2018. https://data.worldbank.org/indicator/NY.GDP.PCAP.CD?locat ions=NG Accessed 26 August 2019.

7. Unemployment rate 2018 Q3. National Bureau of Statistics. Accessed 25 August 2019 at https://www.nigerianstat.gov.ng/

8. Odeyemi IAO, Nixon J. Assessing equity in health care through the national health insurance schemes of Nigeria and Ghana: A review-based comparative analysis. Int $\mathbf{J}$ Equity Health. 2013;12(9):1-18.

9. Cambiaso-Daniel J, Suman OE, Jaco M, et al. Teamwork for total burn care: Burn centers and multidisciplinary burn teams. Total Burn Care. 5th ed. 2018;8-13e.

10. Atanesian M. Social work. North Carolina Jaycee Burn Center. Retrieved from https://www.med.unc.edu/surgery/ burn/aboutus/services/social-work/

11. Greenfield E. The pivotal role of nursing personnel in burn care. Indian J Plast Surg. 2010; (Suppl): S94-S100.

12. Rosenberg L, Rosenberg M, Rimmer RB, et al. Psychosocial recovery and reintegration of patients with burn Injuries. Total Burn Care. 5th ed. 2018;709-720.e4.

13. Thornton A, Battistel L. Working with burns survivors: A social work approach. Australian Social Work. 2001;54(3):93103.

14. Blakeney PE, Rosenberg L, Rosenberg M, et al. Psychosocial care of persons with severe burns. Burns. 2008;34(4):433-440.

15. Waqas A, Naveed S, Bhuiyan MM, et al. Social support and resilience among patients with burn injury in Lahore, Pakistan. Cureus. 2016; 8(11):e867.

16. Pallau N, Kunseberk HW, Noah EM. Psychosocial adjustments 5 years after burn injury. Burns. 2003; 29(2):143-152.

17. Linton KF, Ing MM, Vento MA, et al. From discharge planner to "concierge": Recommendations for hospital social work by clients with intracerebral hemorrhage. Soc Work Public Health. 2015;30(6):486-495.

18. Barrett K. Clinical practice guidelines. Social work (adults). Burn patient management. NSW Statewide Burn Injury Service. 2nd ed.2011. https://www.aci.health.nsw.gov.au/_ data/assets/pdf_file/0007/162637/SBIS_Adult_Social_Work_C PG_new_format.pdf

19. Fraser $\mathrm{MW}$, Lombardi BM, Wu S, et al. Integrated primary care and social work: A systematic review. J Society for Social Work and Research. 2018;9:175-215.

20. Steketee G, Ross AM, Wachman MK. Health outcomes and costs of social work services: A systematic review. Am J Public Health. 2017;107(S3):S256-S266.

21. Barnett BS, Mullenga M, Kiser MM, et al. Qualitative analysis of a psychological supportive counselling group for burn survivors and families in Malawi. Burns. 2017;43(3):602-607.

22. Browne T, Gehlert S, Andrews CM, et al. Strengthening health care systems: Better health across America (Grand Challenges for Social Work Initiative Working Paper No. 22). Cleveland, $\mathrm{OH}$ : American Academy of Social Work \& Social Welfare. 2017.

23. Marino M, Soley-Bori M, Jette AM, et al. Development of a Conceptual Framework to Measure the Social Impact of Burns. J Burn Care Res. 2016; 37(6): e569-e578.

24. Saxe Zerden LD, Lombardi BM, Jones A. Social workers in integrated health care: Improving care throughout the life course. Soc Work Health Care. 2019;58(1):142-149. 